\title{
Effects of hypothermia on lung inflammation in a rat model of meconium aspiration syndrome ${ }^{1}$
}

\author{
Ali Haydar Turhan', Aytuğ Atıcı", Serra Sürmeli"'
}

'Associate Professor, Department of Pediatrics, Division of Neonatology, School of Medicine, University of Başkent, Istanbul, Turkey. Scientific, intellectual, conception and design of the study; acquisition of data, analysis and interpretation of data; technical procedures; statistics analysis; manuscript preparation and writing.

"Professor, Department of Pediatrics, Division of Neonatology, School of Medicine, University of Mersin, Turkey. Scientific and intellectual content of the study, manuscript preparation.

I'IMD, Department of Pediatrics, Division of Neonatology, School of Medicine, University of Mersin, Turkey. Acquisition, analysis and interpretation of data; technical procedures.

\section{Abstract}

Purpose: To evaluate the effects of hypothermia treatment on meconium-induced inflammation.

Methods: Fifteen rats were instilled with human meconium (MEC, $1.5 \mathrm{~mL} / \mathrm{kg}, 65 \mathrm{mg} / \mathrm{mL}$ ) intratracheally and ventilated for 3 hours. Eight rats that were ventilated and not instilled with meconium served as a sham group. In MEC-hypothermia group, the body temperature was lowered to $33 \pm 0.5^{\circ} \mathrm{C}$. Analysis of the blood gases, interleukin (IL)-1B, IL-6, IL-8, and tumor necrosis factor (TNF)- $\alpha$ in bronchoalveolar lavage (BAL) fluid samples, and histological analyses of the lungs were performed.

Results: The BAL fluid TNF- $\alpha, I L-1 \beta, I L-6$ and IL- 8 concentrations were significantly higher in the MEC-hypothermia group than in the MEC-normothermia $(p<0.001, p<0.001, p=0.001$, $p<0.001$, respectively) and sham-controlled groups $(p<0.001, p<0.001, p<0.001, p<$ 0.001 , respectively).

Conclusion: Meconium-induced inflammatory cytokine production is affected by the body temperature control.

Key words: Hypothermia. Meconium. Lung. Respiratory Distress Syndrome, Adult. Rats. 


\section{Introduction}

Meconium aspiration syndrome (MAS) is a severe respiratory disorder that occurs in the term and post-term neonates, and it is still a significant cause of respiratory morbidity and mortality in newborn infants ${ }^{1,2}$. The etiology of the MAS involves inflammatory response characterized by a predominantly neutrophilic infiltrate and stimulation of inflammatory cytokines (e.g., interleukin [IL]-1, IL-6, IL-8 and tumor necrosis factor [TNF]- $\alpha)^{3-5}$. The aim of MAS treatment focuses on minimizing ongoing injury, maintaining oxygenation, and reducing inflammation. Various anti-inflammatory drugs (such as glucocorticoids, phosphodiesterase inhibitors, angiotensin-converting enzyme inhibitors, erythropoietin) have been tested as possible MAS therapies ${ }^{6-9}$. However, therapy of MAS has controversies to show beneficial effects.

In some series, meconium stained liquor has been still reported in $22 \%$ to $55 \%$ of infants with hypoxic-ischemic encephalopathy $(\mathrm{HIE})^{10}$. Therapeutic hypothermia has widely recommended in the standard of care for neonates with $\mathrm{HIE}^{11}$. The mechanisms underlying hypothermia's protective effects are complex and it is thought to attenuates secondary injury of inflammation, decreases vasogenic edema and hemorrhage, prevents neutrophil infiltration, decreases apoptosis and prevents free oxygen radical production $^{12,13}$. Most of the interest focused on brain function and relatively little information has been gained on the effect of therapeutic hypothermia on other body organs and more so on the lungs ${ }^{14}$. Recent experimental studies suggest that hypothermia might have a protective role in several models of lung injury, including ventilator-induced lung injury (VILI) and endotoxin-induced acute lung injury ${ }^{15-18}$. However, the effect of therapeutic hypothermia on inflammatory injury in the meconium-exposed lungs remains unknown.

Considering the above facts, we have analyzed the suitability of the administration of hypothermia on MAS. In this study, we induced a lung injury with local meconium instillation as described previously ${ }^{19}$ and examined the effects of therapeutic hypothermia on pulmonary inflammation on MAS in rats.

\section{- Methods}

This study was approved by the Institutional Committee of Animal Care in Research of Mersin University.

Twenty-seven adult male Wistar rats, weighing 160-240g were studied. Animals were anesthetized with ketamine $(20 \mathrm{mg} /$ $\mathrm{kg})$ and xylazine $(5 \mathrm{mg} / \mathrm{kg}$ ) intraperitoneally (i.p.). Tracheotomy was performed; a 16-G internal diameter catheter was inserted into the trachea, and the animals were placed on a volume-controlled mechanical ventilator (Inspira ASV; Harvard Apparatus, SaintLaurent, QC, Canada). The initial respiratory settings were as follows: fraction of inspired oxygen $\left(\mathrm{FiO}_{2}\right), 1.0$; rate, 40 breaths/min; tidal volume, $4 \mathrm{~mL} / \mathrm{kg}$; and positive end-expiratory pressure (PEEP), $4 \mathrm{cmH}_{2} \mathrm{O}$. Paralysis was induced with vecuronium ( $2 \mathrm{mg} / \mathrm{kg}$ ) i.p. A 26 $G$ polyethylene catheter was inserted into the right carotid artery to obtain blood gas samples and to measure the blood pressure continuously.

Wistar rats were divided into three groups, according to whether meconium had been administered and whether animals were exposed to hypothermia. The study groups were as follows: Sham group; without meconium instillation and maintained in normothermia. Meconium-normothermia group; with meconium instillation and maintained in normothermia. Meconiumhypothermia group; with meconium instillation and maintained in hypothermia. 


\section{Meconium preparation}

Meconium was collected from the first stools of healthy term human neonates. The samples were initially frozen and later pooled and lyophilized. Before the experiment, meconium was diluted with sterile saline to a concentration of $65 \mathrm{mg} / \mathrm{mL}^{20}$. The meconium batch was sterile in culture.

\section{Meconium and hypothermia induction}

In a supine position, a bolus $(1.5 \mathrm{~mL} /$ $\mathrm{kg}$ ) of meconium was instilled slowly through the catheter in the meconium-hypotermia and meconium groups. Animals in the shamcontrolled group was ventilated without meconium instillation. After the stabilization period, ventilator frequency, tidal volume, and PEEP were adjusted to keep partial pressure of arterial carbon dioxide $\left(\mathrm{PaCO}_{2}\right)$ between 35 and $45 \mathrm{mmHg}$ throughout the study. Five percent glucose in saline was infused intra-arterial (i.a.) at $100 \mathrm{~mL} / \mathrm{kg} /$ day.

Rectal temperatures were measured continuously by a temperature probe inserted $0.5 \mathrm{~cm}$ rectally. Body temperature was maintained between $37^{\circ} \mathrm{C}$ and $38^{\circ} \mathrm{C}$ with a radiant warmer in the meconium and sham-controlled groups. Hypothermia was established by cooling circulating water in a closed system. In the meconium-hypotermia group, the rectal temperature was reduced to $33 \pm 0.5^{\circ} \mathrm{C}$ and animals outside the targeted temperature range were excluded from the study. The target temperature was reached in 10 to $15 \mathrm{~min}$.

\section{Tissue samples}

Animals were sacrificed at the end of the study by intravenous administration of a lethal dose of ketamine $(50 \mathrm{mg} / \mathrm{kg})$, after extracting of whole blood. The heart and lungs were removed en bloc. Right lung was saved for later biochemical analyses. Left lung tissue samples were fixed in $10 \%$ buffered formalin, dehydrated, cleared, and embedded in paraffin according to a routine process. Five-micrometer sections were stained with hematoxylin and eosin for light microscopic analysis. To determine the extent and severity of the lung tissue injury, a pathologist (AP) blinded to the grouping of the rats examined the samples and assigned a score from 0 to 4 for three different characteristics: I. extension of leukocyte infiltration $(0=0 \%, 1=0 \%$ to $25 \%, 2=25 \%$ to $50 \%, 3=50 \%$ to $75 \%$, and 4 $=75 \%$ to $100 \%)$; II. amount of intra-alveolar leukocytes ( 0 = none, 1 = occasional, 2 = several leukocytes in the alveoli, 3 = alveoli almost full of leukocytes, and 4 = alveoli distended by tightly packed leukocytes); and III. amount of exudative debris ( 0 = alveoli open, 1 = exudate scarcely seen, 2 = exudate clearly visible, 3 = alveoli almost full of exudate, and $4=$ alveoli distended by exudate). The histologic lung injury score is the sum of these scores ${ }^{19}$.

\section{Bronchoalveolar lavage samples}

Lavage of right lung was performed by instillation of $15 \mathrm{~mL}$ of $0.9 \% \mathrm{NaCl}$ three times and immediate aspiration. BAL fluid was centrifuged ( $350 \mathrm{G},+4^{\circ} \mathrm{C}$ for $10 \mathrm{~min}$ ), and the total alveolar cell counts from cellular debris were performed. Differential cell counts were performed after cytocentrifugation and MayGrünwald-Giemsa staining. Supernatant was collected, frozen at $-70^{\circ} \mathrm{C}$, and later used for determinations of biochemical measurements of TNF- $\alpha$, IL-1 $\beta$, IL- 6 , and IL-8 concentration ${ }^{20}$.

\section{Cytokines}

Rat TNF- $\alpha$ concentration in BAL fluid supernatant was measured with in vitro enzyme-linked immunosorbent assay (Endogen, Inc, Woburn, MA, USA) according to the manufacturer's instructions. Absorbance 
was read at $450 \mathrm{~nm}$ on an EIA reader (Spectra II; Wallac, Turku, Finland) with suitable statistical software (version 2.4; MultiCalc Advanced, Perkin Elmer, Turku, Finland) to calculate the results ${ }^{19}$. IL-6, IL-1 $\beta$, and IL-8 levels were measured using an electrochemiluminescence method with Immulite 2000 systems (Diagnostic Products Corp., Los Angeles, CA, USA).

\section{Statistical analysis}

Statistical analysis was carried out using PASW statistical software (v. 18; SPSS Inc, Armonk, NY, USA). Averages of the results and standard deviations were measured using descriptive statistical methods. Normal distribution for the continuous variable was assessed by Shapiro-Wilk's test, and all data were analyzed with nonparametric tests according to the test results. The median values were compared using Mann-Whitney's $U$ test and Kruskal-Wallis test followed by Dunn's test. Comparison of partial pressure of $\mathrm{O}_{2} \quad\left(\mathrm{PaO}_{2}\right)$ levels and oxygenation index (OI) before and after instillation of meconium were performed with Wilcoxon's signed-rank test. $P$ values less than 0.05 were regarded as statistically significant.

\section{Results}

Twenty-seven male rats were used in the study. Three rats died from hemorrhage during carotid artery catheterization and one rat died before the study was completed. Twenty-three rats completed the study; there were 8,7 and 8 rats in sham-controlled, MECnormothermia and MEC-hypothermia groups, respectively.

Mean weight, mean arterial blood pressure, mean body temperature, mean heart and respiratory rates and were similar between groups at baseline. After 60 minutes of cooling, the mean respiratory rates were significantly higher in MEC-normothermia group [54 \pm 6 (45 -60)] than the MEC-hypothermia group [44 \pm 5 $(40-50)](p=0.002)$.

\section{Oxygenation index}

Results are shown in Figure 1. Intrapulmonary instillation of meconium resulted in increased arterial $\mathrm{OI}\left(\mathrm{FiO}_{2} \times\right.$ mean airway pressure/ $\mathrm{PaO}_{2}$ ) in MEC-normothermia and MEC-hypothermia groups ( $p<0.001$ and $p<0.001$, respectively), whereas no difference was seen in the sham-controlled group. This result suggests that MAS model was successfully constructed. At the end of the study (after three hours) Ol values significantly are still significantly higher in MEC-normothermia group ( $p=0.009)$.

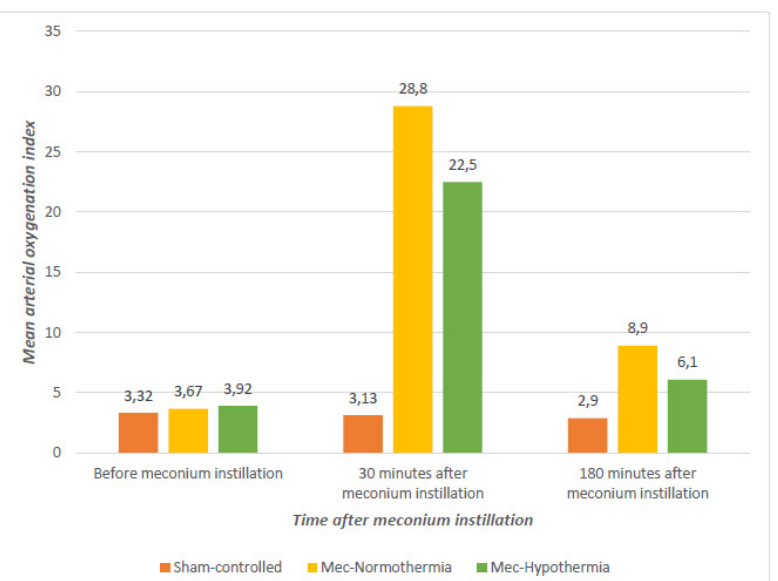

Figure 1 - The mean arterial oxygenation index levels.

\section{Cytokines levels}

As shown in Table 1, intrapulmonary instillation of meconium resulted in an increase in TNF- $\alpha$ ( $p<0.001)$ and IL-6 concentrations $(p<0.001)$ in BAL fluid in MEC-normothermia group compared with the sham-controlled group (Table 1 ).

The BAL fluid TNF- $\alpha$, IL-1 $\beta$, IL- 6 and 
IL-8 concentrations were significantly higher in the MEC-hypothermia group than in the MECnormothermia $(p<0.001, p<0.001, p=0.001$, $p<0.001$, respectively) and sham groups $(p<0.001, p<0.001, p<0.001, p<0.001$, respectively) (Table 1$)$.

Table 1 - BAL fluid levels of IL-1 $\beta$, IL-6, IL-8 and TNF- $\alpha$.

\begin{tabular}{|c|c|c|c|c|}
\hline & $\begin{array}{l}\text { TNF- } \alpha(\mathrm{pg} / \mathrm{ml}) \text {, } \\
\text { median }(\% 25- \\
75)\end{array}$ & $\begin{array}{l}\mathrm{IL-1} \beta(\mathrm{pg} / \mathrm{ml}) \text {, } \\
\text { median }(\% 25- \\
75)\end{array}$ & $\begin{array}{l}\text { IL-6 }(\mathrm{pg} / \mathrm{ml}) \text {, } \\
\text { median (\%25- } \\
75)\end{array}$ & $\begin{array}{l}\mathrm{IL}-8(\mathrm{pg} / \mathrm{ml}), \\
\text { median }(\% 25- \\
75)\end{array}$ \\
\hline $\begin{array}{l}\text { Meconium } \\
\text { Non-Instilled lungs + } \\
\text { Normothermia (Sham, n: 8) }\end{array}$ & $\begin{array}{c}59 \\
(31-81)\end{array}$ & $\begin{array}{c}49 \\
(32-67)\end{array}$ & $\begin{array}{c}27 \\
(13-36)\end{array}$ & $\begin{array}{c}16 \\
(13-23)\end{array}$ \\
\hline $\begin{array}{l}\text { Meconium } \\
\text { Instilled lungs + Normothermia } \\
\text { (MEC-Normothermia, } \mathrm{n}: 7 \text { ) }\end{array}$ & $\begin{array}{c}283^{*} \\
(205-461)\end{array}$ & $\begin{array}{c}19,6 \\
(18-21,2)\end{array}$ & $\begin{array}{c}395^{*} \\
(330-544)\end{array}$ & $\begin{array}{c}87^{*} \\
(72-202)\end{array}$ \\
\hline $\begin{array}{l}\text { Meconium } \\
\text { Instilled lungs + Hypothermia } \\
\text { (MEC-Hypothermia, n: 8) }\end{array}$ & $\begin{array}{c}1153^{*}, a \\
(972-1475)\end{array}$ & $\begin{array}{c}2340 * a \\
(1286-3627)\end{array}$ & $\begin{array}{c}818^{*, f} \\
(668-919)\end{array}$ & $\begin{array}{c}1538^{*}, a \\
(1499-1584)\end{array}$ \\
\hline
\end{tabular}

BAL: bronchoalveolar lavage fluid, IL: interleukin, MEC: meconium, TNF: tumor necrosis factor.

" $p<0.001$ (Compared to the Sham group).

${ }^{a} p<0.001,{ }^{f} p=0.001$ (Compared to the Meconium+ Normothermia group).

Histological markers

No histological differences were found between groups, neither overall score nor specific histologic variables examined.

\section{Discussion}

Although the NICU applications improved, the overall prevalence of morbidity in children born with meconium stained amniotic fluid is still high ${ }^{1,10}$. This present study indicated for the first time the therapeutic effect of hypothermia on meconium induced lung injury in a newborn rat model.

The pathogenesis of MAS is involves that obstruction of the peripheral airways, inactivation of the surfactant function, and induction an inflammatory response through increasing chemotactic activity of polymorphonuclear neutrophils, alveolar macrophages, and stimulating of inflammatory cytokines (e.g., interleukin [IL]-1, IL-6, IL-8 and tumor necrosis factor $[\mathrm{TNF}]-\alpha)^{3,4}$. This inflammatory reaction is associated with decreases in lung compliance and the impairment of pulmonary function ${ }^{21,22}$. In our study, alveolar cytokine levels significantly increased in the meconium-instilled lungs compared to non-instilled controls.

In various models of acute lung injury and injurious mechanical ventilation, hypothermia-treated animals have shown different results. In some of models of acute lung injury, hypothermia-treated animals have shown improved gas exchange and lung mechanics, less pulmonary edema and inflammation, lower histological score of lung injury, and less oxidative stress damage ${ }^{15,17,23,24}$. On the other hand, these beneficial effects have not been shown in the other similar models ${ }^{18,25-27}$.

Altnnsoy et al. ${ }^{15}$ suggested that mild hypothermia therapy may be protective in lipopolysaccharide induced lung injury in immature rats. This effect may be related to milder hypothermia $\left(34.5 \pm 0.5^{\circ} \mathrm{C}\right)$ and younger (seven days old) rats studied without mechanical ventilation. In study of Cruces et 
al. ${ }^{27}$, animals that underwent hypothermia and two hours of deleterious mechanical ventilation (PIP $40 \mathrm{cmH}_{2} \mathrm{O}$ and zero PEEP) had lower serum IL-1 $\beta$ levels, but there had no difference in BAL fluid IL-1 $\beta$ levels. In the study of Morita et al. ${ }^{18}$, hypothermia had not reduce BAL cytokine levels in spite of reducing serum cytokines, during mechanical ventilation BAL levels of TNF- $\alpha$ and IL-1 $\beta$ are higher in hypothermic rats than normothermic ones.

This present study is the first study that shows the effects of hypothermia treatment in a meconium induced lung injury model. Unlike to the of the previous studies on $A L I$, surprisingly, our results indicated the inflammatory role of hypothermia on pulmonary inflammation related to MAS. The lung injury models mentioned above are too different from meconium-induced lung injury model. This may be related to the effect of hypothermia on meconium and the effect of mechanical ventilation. The association of meconium and hypothermia might be causing more obstruction, atelectasis and increasing inflammation in the lung.

A previous report suggested that hyperventilation and reduction of $\mathrm{PaCO}_{2}$ could directly enhance pulmonary impairment ${ }^{28}$. In the present study, the respiratory rate in the MEC-hypothermia group was reduced to keep $\mathrm{PaCO}_{2}$ uniform among subjects, within the normal range of 35-45 torr. As for the effects of different respiratory rates in the initial setting, there has been a theory called "lung rest" that states that the lower the breathing rate, the less the occurrence of lung damage, if the same $\mathrm{PaCO}_{2}$ levels are maintained ${ }^{18}$. In this experiment, the MEC-normothermia group had higher respiratory rates and the MEChypothermia group had lower respiratory rates to maintain the same $\mathrm{PaCO}_{2}$ level. In terms of respiratory rates, the MEC-hypothermia group was more protective from lung damage than the MEC-normothermia group. Therefore, the differences in the respiratory rates might strengthen the significance of the results in the present study.

On histological examination of the lungs, no differences were found between the groups. This may indicate that in lungs, cytokine production occurs before histological alterations are clearly noted.

The major limitation of this study is the dissimilarity of this rat model to a human newborn infant, because of the complex pathophysiology of MAS development. Second, the internal fluid requirement normally varies depending on the body temperature and degree of stress. In the present study, however, the intravenous fluid administration was the same in all groups. Third, $\mathrm{FiO}_{2}$ was set at 1.0 during ventilation in all subjects to avoid effects of reduction of $\mathrm{PaO}_{2}$ arising from pulmonary dysfunction in this study. Some investigators have reported that fever enhanced the toxicity of oxygen ${ }^{29}$.

\section{Conclusions}

Meconium-induced inflammatory cytokine production is affected by the body temperature control. When hypothermia therapy associate with meconium aspiration may induced the inflammatory effects.

\section{References}

1. Dargaville PA, Copnell B, Australian, New Zealand Neonatal $\mathrm{N}$. The epidemiology of meconium aspiration syndrome: incidence, risk factors, therapies, and outcome. Pediatrics. 2006;117(5):1712-21. doi: 10.1542/peds.2005-2215.

2. van lerland $Y$, de Beaufort AJ. Why does meconium cause meconium aspiration syndrome? Current concepts of MAS pathophysiology. Early Hum Dev. 2009;85(10):617-20. doi: 10.1016/j. earlhumdev.2009.09.009.

3. Lee JH, Sung DK, Koo SH, Shin BK, Hong YS, Son CS. Erythropoietin attenuates 
hyperoxia-induced lung injury by downmodulating inflammation in neonatal rats. J Korean Med Sci. 2007;22(6):1042-7. doi: 10.3346/jkms.2007.22.6.1042.

4. Mokra D, Drgova A, Mokry J, Antosova M, Durdik P, Calkovska A. N-acetylcysteine effectively diminished meconium-induced oxidative stress in adult rabbits. J Physiol Pharmacol. 2015;66(1):101-10. doi: 10.1007/5584_2014_4.

5. Nespeca M, Giorgetti C, Nobile S, Ferrini I, Simonato $M$, Verlato $G$. Does whole-body hypothermia in neonates with hypoxicischemic encephalopathy affect surfactant disaturated-phosphatidylcholine kinetics? PLoS One. 2016;11(4):e0153328. doi: 10.1371/journal.pone.0153328.

6. Holopainen R, Laine J, Halkola L, Aho H, Kaapa P. Dexamethasone treatment attenuates pulmonary injury in piglet meconium aspiration. Pediatr Res. 2001;49(2):162-8. doi: 10.1203/00006450-200102000-00006.

7. Turhan AH, Atici A, Muslu N, Polat A, Helvaci I. The effects of pentoxifylline on lung inflammation in a rat model of meconium aspiration syndrome. Exp Lung Res. 2012;38(5):250-5. doi: 10.3109/01902148.2012.676704.

8. Mokra D, Drgova A, Pullmann R, Sr., Calkovska A. Selective phosphodiesterase 3 inhibitor olprinone attenuates meconium-induced oxidative lung injury. Pulm Pharmacol Ther. 2012;25(3):216-22. doi: 10.1016/j. pupt.2012.02.007.

9. Turhan AH, Atici A, Muşlu N, Polat A, Sungur MA. Erythropoietin may attenuate lung inflammation in a rat model of meconium aspiration syndrome. Exp Lung Res. 2016;42(4):199-204. doi: 10.1080/01902148.2016.1190424.

10.Oliveira V, Kumutha JR, Narayanan E, Somanna J, Benkappa N, Bandya P. Hypothermia for encephalopathy in lowincome and middle-income countries: feasibility of whole-body cooling using a low-cost servo-controlled device. BMJ Paediatr Open. 2018;2(1):e000245. doi: 10.1136/bmjpo-2017-000245.

11.Gluckman PD, Wyatt JS, Azzopardi D, Ballard $R$, Edwards AD, Ferriero DM. Selective head cooling with mild systemic hypothermia after neonatal encephalopathy: multicentre randomised trial. Lancet.
2005;365(9460):663-70. doi: 10.1016/ S0140-6736(05)17946-X.

12.Chen X, Li L, Hu J, Zhang C, Pan Y, Tian D. Antiinflammatory effect of dexmedetomidine combined with hypothermia on acute respiratory distress syndrome in rats. J Surg Res. 2017;216:179-84. doi: 10.1016/j. jss.2017.05.014.

13.Polderman KH. Mechanisms of action, physiological effects, and complications of hypothermia. Crit Care Med. 2009;37(7 Suppl):S186-202. doi: 10.1097/ CCM.0b013e3181aa5241.

14.Lista G, Castoldi F, Cavigioli F, Bianchi $S$, Fontana $P$, La Verde A. Ventilatory management of asphyxiated infant during hypothermia. J Matern Fetal Neonatal Med. 2011;24 Suppl 1:67-8. doi: 10.3109/14767058.2011.607615.

15.Altinsoy C, Tuzun F, Duman N, Sever AH, Dilek M, Ozbal S. Effect of induced hypothermia on lipopolysaccharide-induced lung injury in neonatal rats. J Matern Fetal Neonatal Med. 2014;27(4):421-9. doi: 10.3109/14767058.2013.818115.

16.Akinci OI, Celik M, Mutlu GM, Martino JM, Tugrul S, Ozcan PE. Effects of body temperature on ventilator-induced lung injury. J Crit Care. 2005;20(1):66-73. doi: 10.1016/j.jcrc.2004.11.001.

17.Lim CM, Kim MS, Ahn JJ, Kim MJ, Kwon Y, Lee I. Hypothermia protects against endotoxininduced acute lung injury in rats. Intensive Care Med. 2003;29(3):453-9. doi: 10.1007/ s00134-002-1529-6.

18. Morita Y, Oda S, Sadahiro T, Nakamura M, Oshima T, Otani S. The effects of body temperature control on cytokine production in a rat model of ventilator-induced lung injury. Cytokine. 2009;47(1):48-55. doi: 10.1016/j.cyto.2009.04.004.

19. Korhonen K, Soukka H, Halkola L, Peuravuori $\mathrm{H}$, Aho $\mathrm{H}$, Pulkki K. Meconium induces only localized inflammatory lung injury in piglets. Pediatr Res. 2003;54(2):192-7. doi: 10.1203/01.PDR.0000072784.55140.1E.

20.Korhonen K, Kiuru A, Svedstrom E, Kaapa P. Pentoxifylline reduces regional inflammatory and ventilatory disturbances in meconium-exposed piglet lungs. Pediatr Res. 2004;56(6):901-6. doi: 10.1203/01. PDR.0000145256.19073.E4.

21.Davey AM, Becker JD, Davis JM. Meconium 
aspiration syndrome: physiological and inflammatory changes in a newborn piglet model. Pediatr Pulmonol. 1993;16(2):101-8. doi: 10.1002/ppul.1950160205.

22.Pittet JF, Mackersie RC, Martin TR, Matthay MA. Biological markers of acute lung injury: prognostic and pathogenetic significance. Am J Respir Crit Care Med. 1997;155(4):1187205. doi: 10.1164/ajrccm.155.4.9105054.

23.Hong S-B, Koh Y, Lee I-C, Kim MJ, Kim WS, Kim D-S. Induced hypothermia as a new approach to lung rest for the acutely injured lung. Crit Care Med. 2005;33(9):2049-55. doi: 10.1097/01.CCM.0000178186.37167.53.

24.Chin JY, Koh Y, Kim MJ, Kim HS, Kim WS, Kim DS. The effects of hypothermia on endotoxin-primed lung. Anesth Analg. 2007;104(5):1171-8. doi: 10.1213/01. ane.0000260316.95836.1c.

25.Torossian A, Ruehlmann S, Middeke $M$, Sessler DI, Lorenz W, Wulf HF. Mild preseptic hypothermia is detrimental in rats. Crit Care Med. 2004;32(9):1899-903. doi: 10.1097/01.CCM.0000139608.34486.FD.
26.Xiao $H$, Remick DG. Correction of perioperative hypothermia decreases experimental sepsis mortality by modulating the inflammatory response. Crit Care Med. 2005;33(1):161-7. doi: 10.1097/01. CCM.0000151049.19253.54.

27. Cruces $P$, Ronco R, Erranz B, Conget $P$, Carvajal C, Donoso A. Mild hypothermia attenuates lung edema and plasma interleukin-1beta in a rat mechanical ventilation-induced lung injury model. Exp Lung Res. 2011;37(9):54954. doi: 10.3109/01902148.2011.616983.

28.Laffey JG, Engelberts D, Duggan M, Veldhuizen R, Lewis JF, Kavanagh BP. Carbon dioxide attenuates pulmonary impairment resulting from hyperventilation. Crit Care Med. 2003;31(11):2634-40. doi: 10.1097/01.CCM.0000089646.52395.BA.

29. Hasday JD, Garrison A, Singh IS, Standiford T, Ellis GS, Rao S. Febrile-range hyperthermia augments pulmonaryneutrophil recruitment and amplifies pulmonary oxygen toxicity. Am J Pathol. 2003;162(6):2005-17. doi: 10.1016/S0002-9440(10)64333-7.

\section{Correspondence:}

Ali Haydar Turhan

Istanbul Hospital of Başkent University, Neonatal Intensive Care Unit

34662, Istanbul Turkey

Phone: 00905305271997

alihaydarturhan@baskent.edu.tr

Received: Feb 11, 2018

Review: Apr 10, 2018

Accepted: May 12, 2018
Conflict of interest: none

Financial source: none

\begin{abstract}
${ }^{1}$ Research performed at Laboratory Animals and Experimental Research Center, Division of Neonatology, Department of Pediatrics, School of Medicine, Mersin University, Turkey.
\end{abstract}

